\title{
CAREER DEVELOPMENT EVENT PARTICIPATION AND PROFESSIONAL DEVELOPMENT NEEDS OF KANSAS AGRICULTURAL EDUCATION TEACHERS
}

\author{
Clark R. Harris, Assistant Professor \\ Kansas State University
}

\begin{abstract}
Past studies have shown that agricultural education teachers perceive a need for professional development in Career Development Events (CDEs) preparation, but they did not identify the individual CDEs where training was needed. This study examined the CDEs that Kansas schools were participating in at the district and state levels and the CDEs where teachers perceived $a$ need for professional development. A questionnaire was administered via the Internet, and 114 teachers responded. Of the respondents, 83.33\% were interested in a weeklong professional development workshop or graduate course in CDE preparation. CDEs that were identified for professional development, such as agricultural sales, agribusiness management, food science and technology, and agricultural communications were not ranked high in regard to current participation. The livestock evaluation CDE had the highest participation at the district and state levels but ranked 17th in regard to teachers' interest in professional development. It was concluded that teachers participate in CDEs they feel comfortable with and are less likely to participate in CDEs that they feel less familiar. The study also found that most teachers used Internet resources to help prepare students for some CDEs.
\end{abstract}

\section{Introduction/Theoretical Framework}

Classroom and laboratory instruction, leadership development (FFA), and Supervised Agricultural Experience (SAE) programs make up the integrated model for Agricultural Education in the United States (Phipps \& Osborne, 1988). Career Development Events (CDEs) grew out of this model to provide students with the opportunity to apply knowledge and skills gained through these three components (Connors \& Mundt, 2001). The opportunity to apply knowledge and skills is accomplished in practical, real life situations that challenge and motivate students through awards and recognition of their achievement (Beekley \& Moody, 2002; Newcomb, McCracken, \& Warmbrod, 1993). CDEs are competitions that provide agricultural education students with leadership and personal skills that will benefit them in future careers (National FFA Organization, 2000).

Currently, 23 CDEs are hosted by the National FFA Organization (National FFA Organization 2000, 2003) each year. The
CDEs are a combination of team and individual events that are focused on the application of technical agriculture and leadership skills. The College of Agriculture at Kansas State University and the Kansas FFA Association hosts 22 CDEs at the state level. In the technical agriculture CDEs, chapters are supposed to participate at the district level before bringing a team to the state competition. The FFA leadership CDEs including parliamentary procedure, FFA Creed speaking, job interview, public speaking, and extemporaneous public speaking require that students qualify at the district level (Kansas FFA Association, 2005).

Additional CDEs have been implemented in recent years (Connors \& Mundt, 2001), and the content of today's CDEs should be representative of the content being taught in agricultural education. Agricultural education has broadened its view of agriculture and includes topics such as agricultural issues, job interviews, food science, and agricultural communications. As changes occur, teachers have a difficult time staying 
current with the many components of teaching agricultural education, and they have a need to receive professional development (Barrick, Ladewig, \& Hedges, 1983; King \& Garton, 2000; Roberts \& Dyer, 2004). The specific topics that teachers need professional development for should be assessed (Birkenholz \& Harbstreit, 1987; Gamon, Miller \& Roe, 1994; King \& Garton, 2000; Neason, 1992; Roberts \& Dyer, 2004; Washburn, King, Garton, \& Harbstreit, 2001), and university agricultural education faculty that plan and conduct much of the professional development should assess those needs (Barrick et al.; Gamon et al.; Washburn et al.).

The need for professional development to assist teachers in preparing students to compete in CDEs has been presented in several studies. Washburn et al. (2001) reported that "preparing for career development events" was the second highest professional development need of Kansas's agricultural education teachers in the "student and teacher development" category, and it was the 11th highest overall professional development need. Missouri teachers reported that it was their highest "student and teacher development" professional development need (Washburn et al.). Roberts and Dyer (2004) found that both traditionally certified and alternately certified teachers had a high need for professional development in CDEs. Studies have found specific needs of beginning teachers for professional development in contest/CDE preparation (Birkenholz \& Harbstreit,1987; Garton \& Chung, 1995; Layfield \& Dobbins, 2002). Layfield and Dobbins recommended that professional development be provided for beginning teachers because it was an area of high need. The studies have shown that teachers have a need for professional development in CDEs, but they have not addressed the specific CDEs where professional development is needed.

\section{Purpose and Objectives}

The purpose of the study was to determine the CDEs in which schools were currently participating and the CDEs for which agricultural teachers were interested in receiving professional development. The specific objectives of the study were to:

1. Identify the district CDEs in which chapters participated.

2. Identify the state CDEs in which chapters participated.

3. Identify the CDE areas that teachers were interested in receiving professional development.

4. Determine the interest of teachers in receiving the CDE professional development in a weeklong session.

5. Identify Internet resources that teachers were using to enhance their knowledge and to prepare $\mathrm{CDE}$ teams.

\section{Method/Procedures}

This was a descriptive study. The target population was Kansas secondary agriculture teachers $(N=178)$ teaching during the 2005-2006 school year. E-mail addresses were secured from the Kansas FFA Association Office for 177 of the teachers. A listserv mailing list was created from the e-mail addresses. Of the 177 e-mail addresses, 12 e-mail addresses were returned as undeliverable. Current e-mail addresses were secured for five of the 12 e-mail addresses, the teachers were sent the first e-mail, and their e-mail addresses were added to the listserv. This left a usable population of 170 Kansas secondary agricultural educators.

The questionnaire was created by the researcher and contained 10 questions including multiple-response, ranking, and multiple-choice questions. Two multipleresponse questions were included to gather the information about CDE participation. Respondents could check all of the CDEs that their school participated at the district and state level. The respondents' interest in CDE professional development was collected by having respondents rank their top 10 interests from the complete list of CDEs offered at the state level. Respondents were also asked in a multiple-response question if they would be interested in receiving the professional development in a 
weeklong workshop or in a graduate-level course.

Multiple-choice questions were used to collect the demographic information of years of teaching, gender, and FFA district in which the agricultural education teachers taught. The list of CDE resources that were used on the Internet were determined by conversations with teachers, extensive searching of agricultural education Web sites with CDE links, and searching with the Google search engine. The Web sites were listed in a multiple-response question. Respondents were also given an openresponse question to allow them to provide additional Web sites with CDE information.

The questionnaire was placed on quia.com for ease of teachers' response. An e-mail message was sent to the secondary agricultural educators included in the listserv. The message included the purpose of the study, the need for the respondents' assistance, and a link directly to the quiz on quia.com. Within four days, 67 teachers had completed the questionnaire. A reminder e- mail with very similar information was sent four days after the initial e-mail. A second reminder to complete the questionnaire was sent after seven days. Responses were received from $114(67.06 \%)$ secondary agricultural education instructors in Kansas. A limitation to the study is that no additional efforts beside the two follow up e-mails were made, so the findings should only be generalized to the respondents.

\section{Findings}

The largest grouping of teachers to respond $(45.61 \%)$ had more than 15 years of teaching experience (Table 1). The secondlargest grouping of teachers to respond $(28.95 \%)$ was beginning teachers with 1 to 5 years of teaching experience. The large majority of respondents $(91.23 \%)$ were male, and agricultural education teachers responded from all seven of the FFA districts in Kansas, with each district having at least $12 \%$ of the total respondents.

Table 1

Respondents' Years of Teaching Experience $(N=114)$

\begin{tabular}{lcc}
\hline Years of experience & $n$ & $\%$ \\
\hline $1-5$ years & 33 & 28.95 \\
$6-10$ years & 19 & 16.67 \\
$11-15$ years & 10 & 8.77 \\
Over 15 years & 52 & 45.61 \\
\hline
\end{tabular}


The first objective was to identify the district CDEs in which chapters participated (Table 2). The CDE with the highest participation at the district level was the livestock evaluation CDE, with 92.11\% chapter participation. Prepared public speaking ranked next with $83.33 \%$ of the chapters participating at the district level. Dairy cattle evaluation, creed speaking, and horse evaluation all had more than $70 \%$ of the chapters participating.

The second objective was to identify the state CDEs in which chapters participated. Respondents indicated much lower participation (Table 2) at the state level, when compared with participation at the district level. The livestock evaluation CDE had participation from $82(71.93 \%)$ of the respondents' schools, dairy cattle evaluation CDE had 68 schools (59.65\%), and horse evaluation had 59 schools $(51.75 \%)$ participate at the state level. All other CDEs dropped below a 50\% participation level. Prepared public speaking, creed speaking, parliamentary procedure, and job interview dropped considerably due to the Kansas requirement that chapters qualify in these events at the district level to be eligible to compete at the state level. The agricultural issues forum is offered only at the state level, and six $(5.26 \%)$ respondents reported participation.

The third objective was to identify the CDE areas for which teachers were interested in receiving professional development (Table 3). The 23 CDEs that are offered in the state were ranked by teachers from one to 10 in regard to their interest in professional development, with one being the highest. The rankings were weighted so that the items ranked highest by each teacher were given a score of 10 , and the second highest ranking was given a nine, etc. The scores were then totaled, giving the weighted score. The highest-ranking CDE was agricultural sales, with a total weighted score of 406. The agribusiness management and food science and technology CDEs closely followed with 398 and 386 total weighted scores respectively, with seven of the CDEs scoring more than 350 points.

The fourth objective was to determine the interest of teachers in receiving the CDE professional development in a weeklong session. Teachers were given three response options to get professional development in CDEs, first was to take a weeklong workshop, second was to take a week long graduate level summer course, and the third option was neither of the above choices. Sixty-six $(57.89 \%)$ respondents indicated they were interested in taking a weeklong summer graduate level course, with $83.33 \%$ of the respondents indicating interest in participating in either the graduate course or the workshop on CDEs.

The fifth objective was to identify Internet resources that teachers were using to enhance their knowledge and to prepare CDE teams (Table 4). Many teachers responded that he or she used at least one Internet resource to prepare for CDEs. The resources that teachers used most were the Judging 101 Web site with 50 (43.86\%) teacher responses, as well as Agripedia and Texas A\&M Meats that both had 43 $(37.72 \%)$ teacher responses. Five of the Web sites were utilized by $10 \%$ or less of the respondents.

Teachers were also given an open-ended question to provide the names of other Internet resources that were not listed on the questionnaire. The Hoard's Dairyman and Horticopia Web sites were written in the open-ended question. Individual teachers also responded that they use online lesson plans and other resources to prepare students for CDEs from Glen Rose FFA and the Ag Ed Network. 
Table 2

Participation of Respondents' Schools in CDEs at the District and State Levels

\begin{tabular}{|c|c|c|c|c|c|c|}
\hline \multirow[b]{2}{*}{ CDE title } & \multicolumn{3}{|c|}{ District level } & \multicolumn{3}{|c|}{ State level } \\
\hline & Rank & $n$ & $\%$ & Rank & $n$ & $\%$ \\
\hline Livestock Evaluation & 1 & 105 & 92.11 & 1 & 82 & 71.93 \\
\hline Prepared Public Speaking ${ }^{a}$ & 2 & 95 & 83.33 & 14 & 32 & 28.07 \\
\hline Dairy Cattle Evaluation & 2 (tie) & 95 & 83.33 & 2 & 68 & 59.65 \\
\hline Creed Speaking $^{\mathrm{a}}$ & 4 & 93 & 81.58 & $15(\mathrm{tie})$ & 28 & 24.56 \\
\hline Horse Evaluation & 5 & 87 & 76.32 & 3 & 59 & 51.75 \\
\hline Parliamentary Procedure $^{\mathrm{a}}$ & 6 & 77 & 67.54 & 20 & 21 & 18.42 \\
\hline Land Judging & $6($ tie $)$ & 77 & 67.54 & 9 & 39 & 34.21 \\
\hline Meats Evaluation & 8 & 76 & 66.67 & 4 & 53 & 46.49 \\
\hline Dairy Foods & 9 & 67 & 58.77 & 5 & 46 & 40.35 \\
\hline Entomology & 10 & 66 & 57.89 & 6 & 44 & 38.60 \\
\hline Job Interview $^{\mathrm{a}}$ & 11 & 60 & 52.63 & 19 & 22 & 19.30 \\
\hline Floriculture & 12 & 59 & 51.75 & 7 & 43 & 37.72 \\
\hline Poultry Evaluation & 13 & 57 & 50.00 & 8 & 42 & 36.84 \\
\hline Extemporaneous Public Speakinga & 13(tie) & 57 & 50.00 & 17 & 25 & 21.93 \\
\hline Agricultural Sales & 15 & 53 & 46.69 & $15(\mathrm{tie})$ & 28 & 24.56 \\
\hline Food Science \& Technology & 16 & 51 & 44.74 & 10 & 36 & 31.58 \\
\hline Agribusiness Management & 17 & 49 & 42.98 & 12 & 34 & 29.82 \\
\hline Nursery/Landscape & 18 & 47 & 41.23 & 13 & 33 & 28.95 \\
\hline Agricultural Technology Management & 19 & 46 & 40.35 & 21 & 19 & 16.67 \\
\hline Agronomy & 20 & 45 & 39.47 & 11 & 35 & 30.70 \\
\hline Agricultural Communications & 21 & 18 & 15.79 & 18 & 24 & 21.05 \\
\hline Environmental \& Natural Resources & 22 & 11 & 9.65 & $22($ tie $)$ & 6 & 5.26 \\
\hline Agricultural Issues Forum & & & & 22 (tie) & 6 & 5.26 \\
\hline Forestry (Not offered in the state) & & & & & & \\
\hline
\end{tabular}

Note. Some CDEs at the state level require chapters or individuals to qualify at the district level. ${ }^{a} \mathrm{CDEs}$ that require schools to qualify at the district level to be able to compete at the state level. 
Table 3

Respondents' Rankings of Their Interest in CDE Professional Development

Response Tallies by Ranking

\begin{tabular}{|c|c|c|c|c|c|c|c|c|c|c|c|}
\hline & 1 & 2 & 3 & 4 & 5 & 6 & 7 & 8 & 9 & 10 & Total $^{\mathrm{a}}$ \\
\hline Agricultural Sales & 8 & 8 & 10 & 8 & 7 & 8 & 3 & 4 & 3 & 6 & 406 \\
\hline Agribusiness Management & 13 & 13 & 6 & 4 & 3 & 4 & 5 & 3 & 3 & 2 & 398 \\
\hline Food Science \& Technology & 11 & 5 & 6 & 10 & 4 & 4 & 9 & 3 & 9 & 6 & 386 \\
\hline Agricultural Communications & 9 & 11 & 11 & 3 & 3 & 6 & 1 & 4 & 6 & 1 & 375 \\
\hline Meats Evaluation & 10 & 7 & 8 & 3 & 8 & 4 & 5 & 3 & 5 & 5 & 360 \\
\hline Dairy Foods & 5 & 10 & 7 & 10 & 8 & 2 & 3 & 2 & 4 & 2 & 352 \\
\hline Agronomy & 10 & 6 & 8 & 4 & 6 & 4 & 5 & 6 & 3 & 5 & 351 \\
\hline Entomology & 3 & 4 & 4 & 11 & 4 & 9 & 5 & 7 & 3 & 7 & 298 \\
\hline Agricultural Issues Forum & 6 & 6 & 3 & 6 & 6 & 2 & 9 & 2 & 4 & 3 & 279 \\
\hline Nursery/Landscape & 5 & 3 & 5 & 5 & 7 & 5 & 4 & 6 & 5 & 5 & 268 \\
\hline Floriculture & 2 & 6 & 8 & 3 & 6 & 3 & 7 & 6 & 4 & 3 & 267 \\
\hline Agricultural Technology & 9 & 3 & 6 & 5 & 2 & 4 & 3 & 3 & 4 & 4 & 265 \\
\hline \multicolumn{12}{|l|}{ Management } \\
\hline Environmental \& Natural Resources & 9 & 3 & 5 & 1 & 2 & 6 & 4 & 4 & 5 & 2 & 246 \\
\hline Parliamentary Procedure & 5 & 2 & 4 & 5 & 5 & 7 & 4 & 4 & 4 & 4 & 240 \\
\hline Horse Evaluation & 2 & 3 & 5 & 9 & 4 & 3 & 7 & 3 & 5 & 1 & 237 \\
\hline Land Judging & 2 & 7 & 2 & 4 & 6 & 6 & 3 & 4 & 2 & 6 & 227 \\
\hline Livestock Evaluation & 5 & 5 & 3 & 4 & 4 & 1 & 4 & 2 & 6 & 2 & 212 \\
\hline Job Interview & 1 & 2 & 2 & 4 & 5 & 4 & 4 & 6 & 2 & 8 & 168 \\
\hline Dairy Cattle Evaluation & 0 & 4 & 0 & 1 & 7 & 6 & 4 & 4 & 4 & 3 & 154 \\
\hline Poultry Evaluation & 2 & 2 & 1 & 3 & 5 & 4 & 4 & 1 & 6 & 6 & 154 \\
\hline Prepared Public Speaking & 2 & 1 & 2 & 0 & 0 & 3 & 2 & 3 & 2 & 5 & 86 \\
\hline Creed Speaking & 1 & 2 & 1 & 2 & 1 & 0 & 0 & 2 & 2 & 1 & 67 \\
\hline Extemporaneous Public Speaking & 0 & 0 & 3 & 1 & 2 & 1 & 1 & 2 & 4 & 1 & 67 \\
\hline
\end{tabular}

${ }^{\mathrm{a}}$ Total $=(n$ ranking $\mathrm{CDE}$ as 1$) \times 10+(n$ ranking $\mathrm{CDE}$ as 2$) \times 9 \ldots(n$ ranking $\mathrm{CDE}$ as 1$) \times 1$ 
Table 4

Internet CDE Resources that Teachers Currently Use

\begin{tabular}{lcc}
\hline CDE online resources & $n$ & $\%$ \\
\hline Judging 101 - Livestock judging & 50 & 43.86 \\
Agripedia - Online CDE Resources & 43 & 37.72 \\
Texas A\&M Meats & 43 & 37.72 \\
KSU Horse Judging & 42 & 36.84 \\
Georgia Agriculture Education - Exams & 31 & 27.19 \\
Nebraska Meats & 30 & 26.32 \\
Landjudging.com & 30 & 26.32 \\
AMSA Meats & 25 & 21.93 \\
OSU Floriculture ID & 25 & 21.93 \\
OSU Nursery/Landscape ID & 21 & 18.42 \\
Parliamentary Procedure Instructional Materials Service & 16 & 14.04 \\
Washington State CDE - Exams \& Practicums & 13 & 11.40 \\
Minnesota State CDE - Exams in Word \& pdf & 11 & 9.65 \\
Purdue Meat Evaluation & 10 & 8.77 \\
Yellowsheet Meats & 10 & 8.77 \\
Missouri FFA Farm Business Management Tests & 8 & 7.02 \\
Bug Bios - Insect Pictures & 7 & 6.14 \\
Cagles Parliamentary Procedure & 0 & 0.00 \\
\hline
\end{tabular}

\section{Conclusions, Implications, and Recommendations}

Many of the CDEs had extensively lower attendance at the state level. Five of the CDEs required students or teams to qualify at the district level. It would be expected that when students had to qualify, that less schools would be able to compete at the state level in the events. All five CDEs that required qualification ranked in the top 13 CDEs in participation at the district level, but they all ranked 14 or below in participation at the state level. When the five CDEs that require qualification are taken into consideration, then it is expected that the other CDEs adjusted up on the ranking at the state level. Assisting teachers to gain a better understanding of the five CDEs that require qualification may allow their schools to compete at the state level, but the number of individuals competing will probably not increase appreciably.

Nine of the CDEs that did not require qualification had a drop in participation of $30 \%$ or more at the state level. This could be for a variety of reasons, including the teachers not feeling that they have sufficient knowledge in the CDE. Further study should be done to determine why schools participate in some events at the district level but not at the state level.

Teachers voiced their interest in receiving professional development in $\mathrm{CDE}$ preparation, which supports previous research (Birkenholz \& Harbstreit, 1987; 
Garton \& Chung, 1995; Layfield \& Dobbins, 2002). It was reported that $83.33 \%$ of the teachers responding were interested in attending either a weeklong workshop or a summer graduate course. With the high interest in the area of CDEs, a professional development activity should be implemented. A beneficial approach would be to offer teachers an opportunity to attend the same weeklong professional development on CDEs as either a workshop or a summer graduate course.

The 10 CDEs that teachers ranked highest in having an interest in attending professional development through a weeklong workshop/course all had less than $50 \%$ participation at the state level. Seven of them had less than $50 \%$ participation at the district level. This would tend to indicate that teachers do not participate in these CDEs as often when they are not as familiar with the CDEs. Agricultural educators should examine if low participation in some CDEs is due to lack of familiarity or due to other reasons. The inverse of the above observation was seen in the livestock evaluation CDE, which ranked highest in participation at both the district and state level but was ranked 17th of 23 for teacher interest in professional development. It is possible that teachers either felt that they knew a lot about the livestock evaluation $\mathrm{CDE}$ or that there were many other resources available. One example of a resource that was available for livestock evaluation was the Judging 101 Web site, which was the toprated Internet resource utilized by the respondents.

The study indicated that many teachers use resources on the Internet to prepare students for CDEs, but less than $43.86 \%$ of the teachers used any specific Internet resource, and five of the Web sites were utilized by $10 \%$ or less of the respondents. Both of these examples may be because teachers are unfamiliar with the resources that are available or have better resources available. Teachers should be informed of the Internet resources that are currently available to prepare for CDEs, and agricultural educators should continue to search for undiscovered Internet resources that are available online. Research should be done to determine why teachers are either using or not using resources that are available on the Internet. It would be beneficial to determine what other resources teachers would like to have made available on the Internet.

Researchers should examine different methods to deliver professional development about CDE preparation to teachers such as short inservice or online training. Also, research should be done to determine if teachers in other states have similar interest for professional development in particular CDEs.

\section{References}

Barrick, R. K., Ladewig, H. W., \& Hedges, L. E. (1983). Development of a systematic approach to identifying technical inservice needs of teachers. Journal of the American Association of Teacher Educators in Agriculture, 24(1), 13-19.

Beekley, B., \& Moody, L. (2002). Career development events: An example of authentic learning. The Agricultural Education Magazine, 75(1), 16-17.

Birkenholz, R. J., \& Harbstreit, S. R. (1987). Analysis of the inservice needs of beginning vocational agriculture teachers. Journal of the American Association of Teacher Educators in Agriculture, 28(1), 41-49.

Connors, J. J., \& Mundt, J. P. (2001). Experiential education and career development events. The Agricultural Education Magazine, 73(6), 6-7.

Gamon, J., Miller, W. W., \& Roe, R. (1994). Inservice needs and delivery method preferences of Iowa high school agriculture teachers. Proceedings of the 21st National Agricultural Education Research Conference, 21, 216-221.

Garton, B. L., \& Chung, N. (1995). An analysis of the inservice needs of beginning teachers of agriculture. Proceedings of the 22nd Annual National Agricultural Education Research Meeting, Denver, CO, $22,77-83$. 
King, B. O., \& Garton, B. L. (2000). The professional development needs of teachers of agriculture. Proceedings of the 54th Annual Central Region Research Conference in Agricultural Education, 54, 152-161.

Layfield, K. D., \& Dobbins, T. R. (2002). Inservice needs and perceived competencies of South Carolina agricultural educators. Journal of Agricultural Education, 43(4), 46-55.

Kansas FFA Association. (2005). Career development events overview. Retrieved November 15, 2005, from the Kansas FFA Association Web site, http://www.hpj.com/ wsdocs/ffa/association.cfm

National FFA Organization. (2000). FFA Student Handbook. Indianapolis, IN: Author.

National FFA Organization. (2003). National FFA Career Development Events Handbook. Indianapolis, IN: Author.

Neason, A. (1992). Analysis of agriscience teacher inservice needs.
Proceedings of the 19th National Agricultural Education Research Conference, 19, 312-320.

Newcomb, L. H., McCracken, J. D., \& Warmbrod, J. R. (1993). Methods of Teaching Agriculture. Danville, IL: Interstate.

Phipps, L. J., \& Osborne, E. W. (1988). Handbook on Agricultural Education in Public Schools. Danville, IL: Interstate Printers \& Publishers.

Roberts, T. G., \& Dyer, J. E. (2004). Inservice needs of traditionally and alternatively certified agriculture teachers. Journal of Agricultural Education, 45(4) 5770 .

Washburn, S. G., King, B. O., Garton, B. L., \& Harbstreit, S. R. (2001). A comparison of the professional development needs of Kansas and Missouri teachers of agriculture. Proceedings of the 28th National Agricultural Education Research Conference, 28, 396-408.

CLARK R. HARRIS is an Assistant Professor in the Department of Secondary Education at Kansas State University, 364 Bluemont Hall, Manhattan, KS 66506. E-mail: clarkh@ksu.edu. 